\title{
Research on a High-Speed and Heavy-Duty Closed-Loop Drive System of a Two-Phase Hybrid Stepping Motor Based on a Hybrid Controller
}

\author{
Zhou Yansuo $\mathbb{D},{ }^{1,2}$ Leng Yonggang $\mathbb{D}^{1},{ }^{1}$ Lu Wenqi $\mathbb{D},{ }^{3}$ Li Yu, ${ }^{4}$ Li Qingmian, ${ }^{2}$ and Wu Di ${ }^{3}$ \\ ${ }^{1}$ School of Mechanical Engineering, Tianjin University, Tianjin 300072, China \\ ${ }^{2}$ Zhejiang Institute of Industry and Information Technology, Hangzhou 310006, China \\ ${ }^{3}$ School of Mechanical Engineering and Automation, Zhejiang Sci-Tech University, Hangzhou 310018, China \\ ${ }^{4}$ Zhejiang Institute of Modern Agricultural Equipment Design and Research, Hangzhou 310009, China
}

Correspondence should be addressed to Leng Yonggang; leng_yg@tju.edu.cn and Lu Wenqi; luwenqi@zstu.edu.cn

Received 10 May 2021; Accepted 19 July 2021; Published 26 August 2021

Academic Editor: Yuanpeng Zhang

Copyright (C) 2021 Zhou Yansuo et al. This is an open access article distributed under the Creative Commons Attribution License, which permits unrestricted use, distribution, and reproduction in any medium, provided the original work is properly cited.

Low load capacity and poor positioning accuracy of stepper motors in high-speed operation are currently two of the bottlenecks that limit their application in high-speed and heavy-duty drive applications. To solve this problem, a hybrid controller is proposed for the high-speed heavy-duty closed-loop stepper motor driving system, which includes two core contents. First, for the position control, a hybrid controller based on position error for open-loop/closed-loop automatic switching-combined spatial current given amplitude and angle automatic adjustment is proposed. Secondly, an advanced angle compensation strategy based on error-integrated feedforward is adopted to compensate for the electrical angle of the combined space current vector. To verify the effectiveness of the proposed method, theoretical analysis and system development as well as testing are carried out. Compared with the traditional open-loop drive system, results show that the maximum operating speed and maximum torque of the newly developed drive system based on the proposed method are improved by $50 \%$ and $81.25 \%$, respectively. And at the same set speed and position, the response speed is faster and the accuracy of the steady-state process is higher. In the case of setting higher running speed and load torque, the drive system also maintains high-precision operation.

\section{Introduction}

A two-phase hybrid stepping motor is widely used in $3 \mathrm{D}$ printing, electric vehicles, textile machinery, industrial robots, etc. due to its simple control, accurate positioning, low cost, etc. [1-5]. But most of the current applications of the stepping motor is mainly open-loop control, which has shortcomings such as low-frequency oscillation, low speed, poor load capacity, and out of step. In recent years, with the continuous development of power electronics technology and modern industrial application requirements, higher requirements (high precision, high response, and high load capacity) for the existing open-loop control and the control performance of stepper motors are put forward. The traditional open-loop methods $[4,5]$ can no longer meet the driving requirements.
Some improved control strategies have also presented in recent years. A nuclear step control strategy is proposed for a two-phase hybrid stepping motor [6,7]. Based on the traditional open-loop control of the stepper motor, the real-time rotor position feedback is introduced by detecting the nuclear step counter. Position compensation is completed by increasing or decreasing control pulses when out of step or beyond step. The accuracy of its position was ensured to some extent, but this control strategy cannot increase the output torque when the motor is out of step or blocked. So the load capacity using this strategy is weak. A power angle control strategy of the stepping motor is proposed in $[8,9]$ by monitoring the power angle in real time and ensuring that the power angle does not exceed the steady-state operation of the motor by adjusting the terminal voltage of the motor phase winding and the rotor speed of the stepping motor. When the power 
angle is close to the maximum power angle of the stepper motor in steady-state operation, the excitation current of the motor winding is controlled to achieve the purpose of enhancing the antiload fluctuation capability of the stepping motor. The method can improve the load capacity of the motor. However, the acquirement of the stepping motor power angle is extremely complicated. So it is difficult to realize in actual occasion. Moreover, the test process finds that the motor driven by the method has a higher temperature rise and lowers the service life of the motor.

Research efforts have also been made to implement sensorless control for stepper motors [10-15]. The majority of these sensorless methods $[11,12]$ are based on observer techniques and Kalman filtering. The tuning of such observers for sensorless motor control is complex and time-consuming. Moreover, most observer-based sensorless techniques [11, 12] rely on models containing load parameters such as inertia and friction. Load-dependent parameters of the motor control system are difficult to determine and often vary over time. On the other hand, the rotor position based on the response of high-frequency test signals is estimated in [12]. These methods estimate the rotor position accurately, even at low speeds where observer-based methods often fail. However, these methods need access to the power electronics to generate the desired test pulses. This hinders implementation at existing stepping motor controllers. The sensorless algorithm, described in [13-15], estimates the load angle. In contrast to more complex observer algorithms, this estimator does not depend on mechanical load parameters and is characterized by a low computational cost. However, the system designed by the sensorless estimation method has poor high-speed load capacity and low positioning accuracy, which cannot meet the requirements of high-speed and high-load driving.

For this purpose, some field-oriented controllers with position feedback and vector control algorithms are used to drive stepper motors [16-24]. This method improves the positioning accuracy of the stepping motor, but compared with the general DC or AC motor, the air gap of the hybrid stepping motor is much smaller. The reluctance torque has a large influence on the electromagnetic torque and cannot be ignored. It is more complicated to obtain accurate torque expression. The closed-loop drive system designed by this scheme has a relatively low load capacity during high-speed operation. To reduce the torque ripple [18-21] or improve the maximum speed [22], some research efforts have been carried out, sometimes even using artificial intelligence techniques such as neural networks $[23,24]$ and fuzzy control [25], but these algorithms are more complex to implement and will be limited by hardware costs.

Therefore, the above existing research work focuses on how to improve the positioning accuracy of the stepping motor and has achieved certain improvements. Some applications (engraving machine, stripping machine, etc.) have been applied in some occasions where the running speed and load capacity are not high (generally between 300 and $600 \mathrm{r} / \mathrm{min}$ ). However, in some occasions where the running speed is higher (usually between 800 and $1200 \mathrm{r} / \mathrm{min}$ ) and the load capacity is strong (template machine, embroidery machine, etc.), the current algorithm cannot meet the driving requirements, and it is urgent to introduce a control method to improve the high-speed load capacity of the motor. To this end, to improve the load capacity and positioning accuracy of the motor at high speed, the control method and system in this paper are proposed to carry out theoretical and experimental research.

\section{The Closed-Loop Driving Method Based on the Hybrid Controller}

To improve the positioning accuracy and load capacity of the stepping motor under high-speed operation, this paper proposes a high-speed heavy-duty driving method and system based on a hybrid controller. The principal block diagram is shown in Figure 1. It is composed of a position hybrid controller, a current loop PI regulator, Clark transform, a two-phase space vector modulation algorithm, an $\mathrm{H}$-bridge inverter, lead angle compensation, and a hybrid stepping motor (self-contained encoder). The control scheme of the system adopts the position/current two-loop control structure. Compared with the existing position/speed/current three-loop closedloop control structure, the following improvements are made:

(1) Position control proposes an open loop based on position error

In position control, a hybrid controller is proposed, which can automatically switch the open loop/closed loop according to the position error and automatically adjust the given amplitude and angle of the synthetic space current. Its output is the two-phase space current vector of the synthetic current space vector in the stator coordinate system.

(2) Propose the error-integrated feedforward-based advancement

The angle compensation strategy compensates for the electrical angle of the resultant space current vector. The two improved methods are specifically described below.

The main parameters involved in the control system are as follows:

$i_{\text {ref }}$ is the current reference vector, $\theta_{g}$ is the current vector angle, $i_{\alpha \text { ref }}$ is the $\alpha$-axis current reference vector, $i_{\beta \text { ref }}$ is the $\beta$ -axis current reference vector, $i_{\text {openhold }}$ is the open-loop hold current, Ip is the maximum current output value of the driver, $e_{\text {pos }}$ is the position error, and $\theta_{i}$ is the integral calculation value of the position error.

2.1. Position Hybrid Controller. Based on the analysis of the advantages and disadvantages of the current position, speed, and current three-loop vector control scheme of the permanent magnet AC servo system and the stepping motor open-loop control scheme, a hybrid controller is proposed, which is based on position error for open-loop/closed-loop automatic switching, and the assignment of the current vector magnitude $i_{\text {ref }}$ and angle $\theta_{g}$ of the combined space is automatically adjusted according to the position error. Its principal block diagram is shown in Figure 2. The value of 


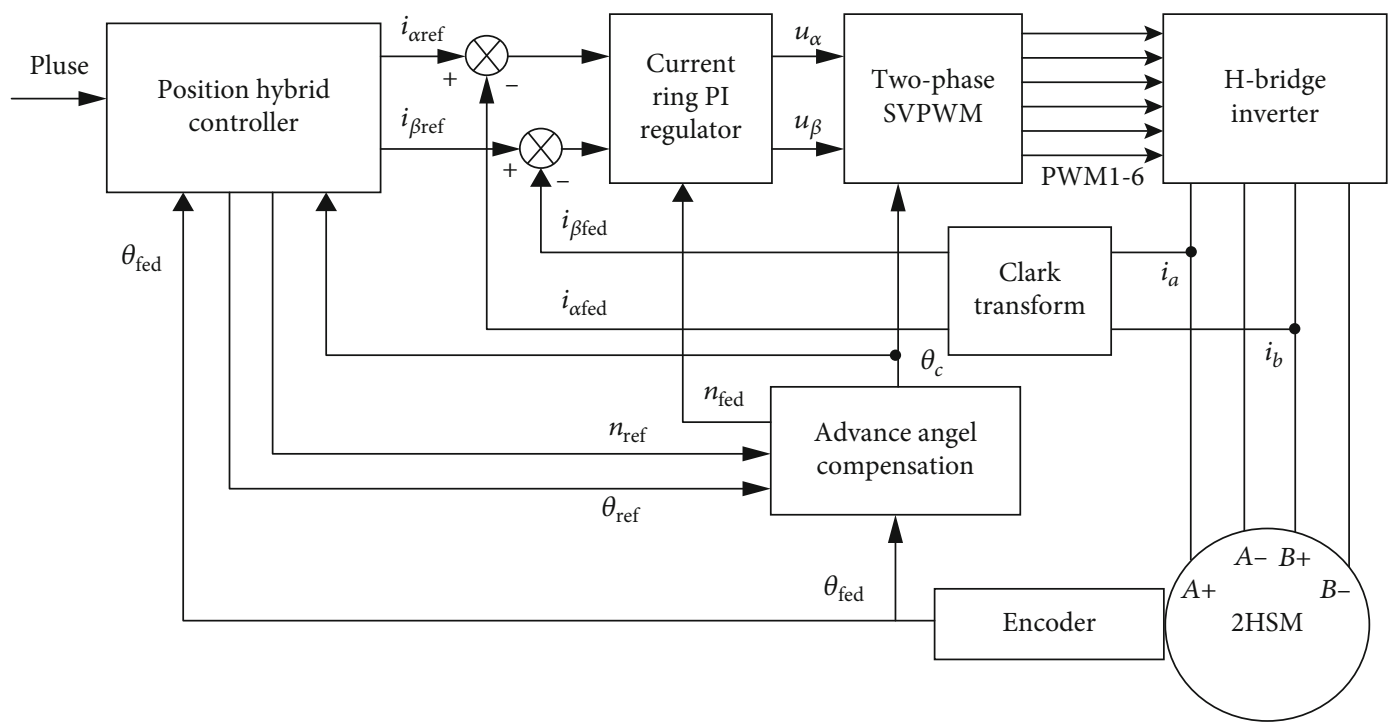

FIGURE 1: The system principle block diagram of the proposed scheme.

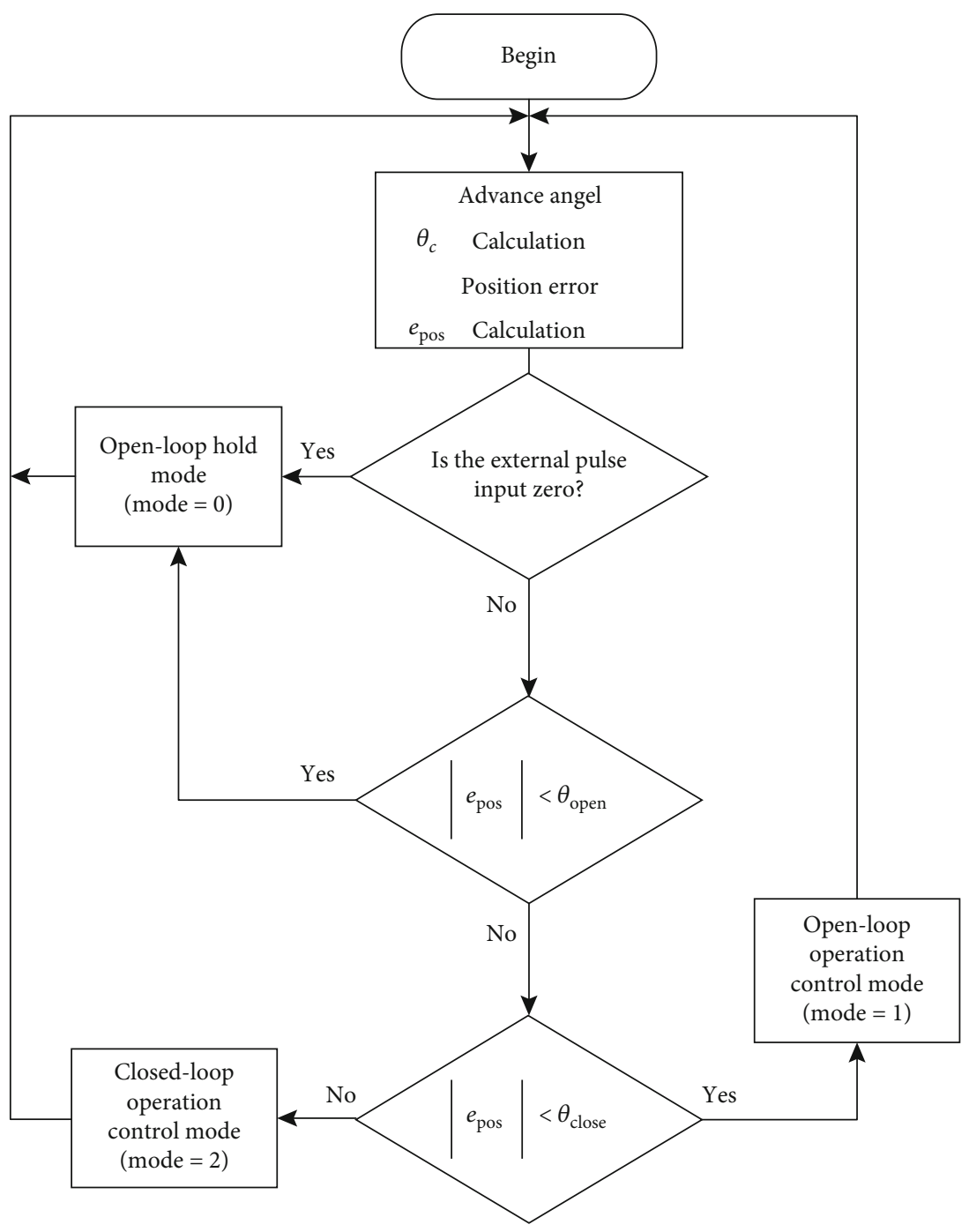

FIGURE 2: The principle block diagram of the hybrid controller based on position error automatic switching control mode. 


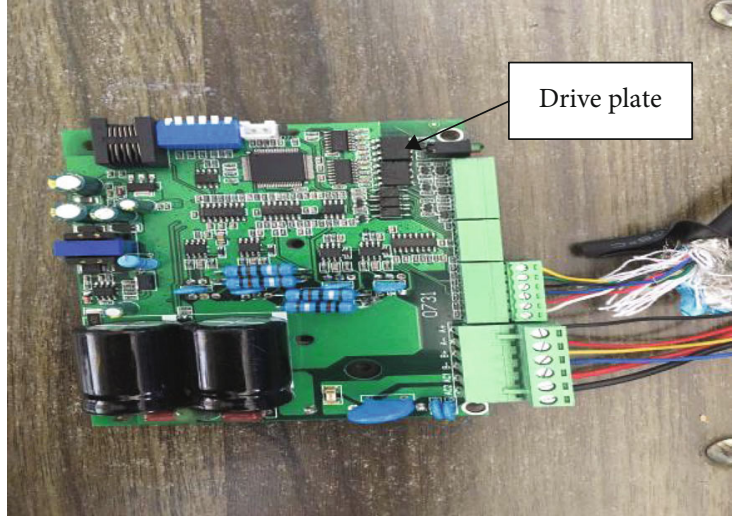

Drive system

(a) Drive system

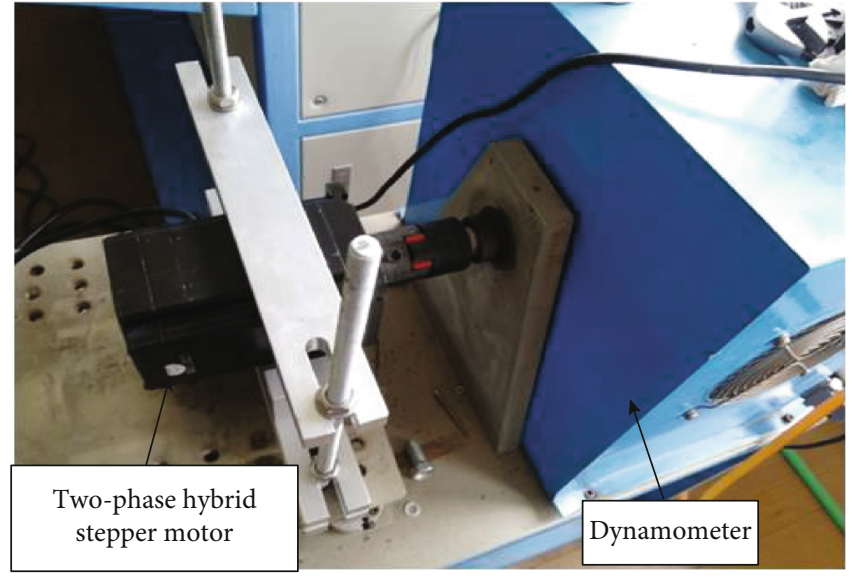

Stepper motor and loading equipment

(b) Stepper motor and loading equipment

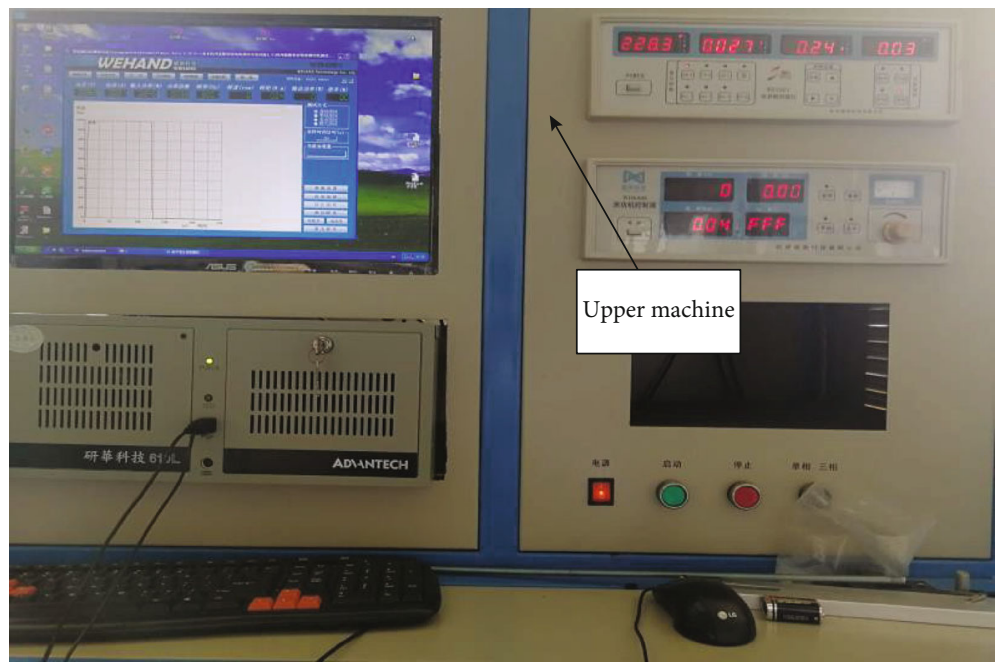

Waveform acquisition system of upper computer

(c) Waveform acquisition system of the upper computer

Figure 3: Test platforms.

the current vector amplitude $i_{\text {ref }}$ is adjusted according to formula (1), and the current vector angle $\theta_{g}$ is adjusted according to formula (2). When $i_{\text {ref }}$ and $\theta_{g}$ are assigned, the hybrid controller can calculate the values of $i_{\alpha \mathrm{ref}}$ and $i_{\beta \mathrm{ref}}$ in the stationary coordinate system according to formula (3).

The working principle of the hybrid controller is briefly described as follows:

(1) When the drive system does not receive the external pulse signal, the motor enters the open-loop hold mode (mode $=0)$. At this time, set the amplitude $i_{\text {ref }}$ of the composite space current vector to the openloop hold current $i_{\text {openhold }}$, and set the composite space current vector angle $\theta_{g}$ to $\theta_{i}$, where $i_{\text {openhold }}=$ $P_{\text {openhold }} \times \mathbf{I} \mathbf{p}$, where Ip is the maximum current output value of the driver and $P_{\text {openhold }}$ is the percentage of the open-loop holding current and the maximum current output of the driver. $\theta_{i}$ is the integral calcula- tion value of the position error $e_{\text {pos }}$, and the integral of the position error is used as a calculation to improve the positioning accuracy and output when the motor is stationary

(2) When the drive system receives the external pulse input signal and when the absolute value of the position error is less than or equal to $\theta_{\text {close }}$, the motor adjusts the control mode according to the position error and the magnitude of the lead compensation angle: when the position error and the lead angle are both less than or equal to $\theta_{\text {close }}$, the system enters the open-loop hold mode (mode $=0$ ). At this time, set the amplitude $i_{\text {ref }}$ of the composite space current vector to $i_{\text {openhold }}$ and set the angle $\theta_{g}$ of the composite space current vector to $\theta_{i}$; when the position error and the lead angle are both greater than $\theta_{\text {open }}$ and less than or equal to $\theta_{\text {close }}$, it enters the open-loop operation control mode (mode $=1$ ), and set the amplitude 
TABle 1: Parameters related to the stepper motor and drive system.

\begin{tabular}{lccc}
\hline Variable name & Numerical value & Variable name & Numerical value \\
\hline Polar logarithm & 50 & Rotor inertia & $2.8\left(\mathrm{~kg} \cdot \mathrm{cm}^{2}\right)$ \\
Rated speed $n_{s}$ & $1500 \mathrm{r} / \mathrm{min}$ & Rated phase current & $6 \mathrm{~A}$ \\
Hold torque & $8 \mathrm{~N} \cdot \mathrm{m}$ & $P_{\text {closehold }}$ & $100 \%$ \\
Inductance & $\mathrm{mH}$ & $P_{\text {openhold }}$ & $40 \%$ \\
Resistance & $\Omega$ & $\theta_{\text {open }}$ & 90 electric angle \\
Maximum output current of the driver & $8 \mathrm{~A}$ & $\theta_{\text {close }}$ & 135 electric angle \\
Encoder line number & 1000 & $l$ & 1.5 \\
\hline
\end{tabular}

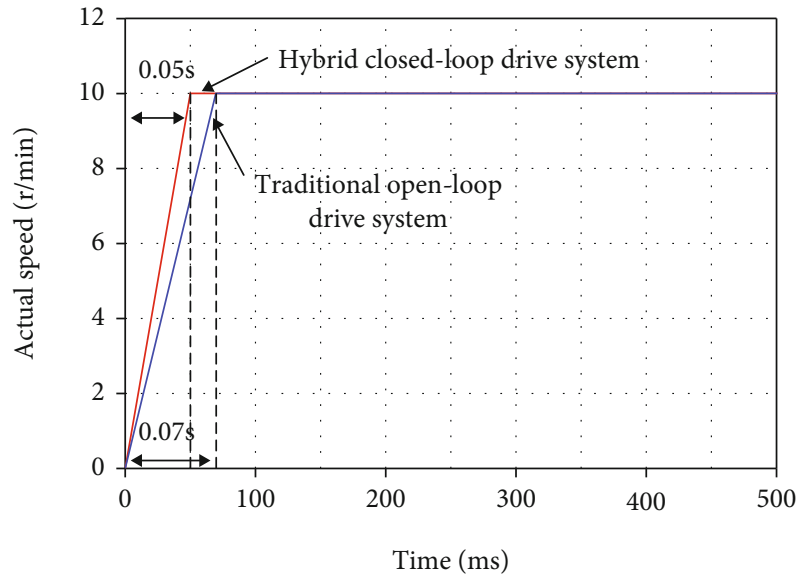

Figure 4: Comparison of motor speed curves at a given speed $10 \mathrm{r} / \mathrm{min}$.

$i_{\text {ref }}$ of the combined space current vector to the openloop running current $i_{\text {openrun }}$, wherein the calculation formula of $i_{\text {openrun }}$ is shown in formula (4), which adjusts in real time according to the position error; set the angle $\theta_{g}$ of the combined space current vector to the given position angle $\theta_{\text {ref }}$. It adjusts the positioning accuracy and updates the real-time angle according to the externally set subdivision value

(3) When the drive system receives the external pulse input signal and when the position error is greater than $\theta_{\text {close }}$, the motor enters the closed-loop operation control mode (mode $=2)$. At this time, the amplitude $i_{\text {ref }}$ of the combined space current vector is set as the closed-loop running current $i_{\text {closerun }}$; in the setting space, the angle $\theta_{g}$ of the combined current vector is set to $\theta_{\text {fed }}+\theta_{c}$, where $i_{\text {closerun }}=$ $P_{\text {closehold }} \times \mathbf{I p}$, where $P_{\text {closehold }}$ is the percentage of the closed-loop operating current and the maximum current output of the driver, $\theta_{\text {fed }}$ is the angular value of the actual feedback of the encoder, and $\theta_{c}$ is based on the position error and speed error compensation calculation. The obtained lead angle is used to improve the motor output and positioning accuracy during high-speed operation

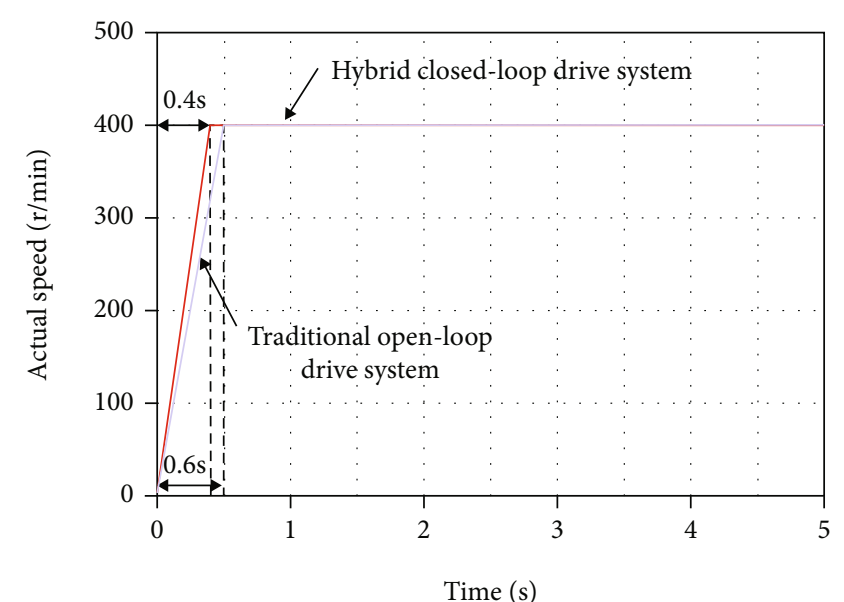

FIgURE 5: Comparison of motor speed curves at a given speed $400 \mathrm{r} / \mathrm{min}$.

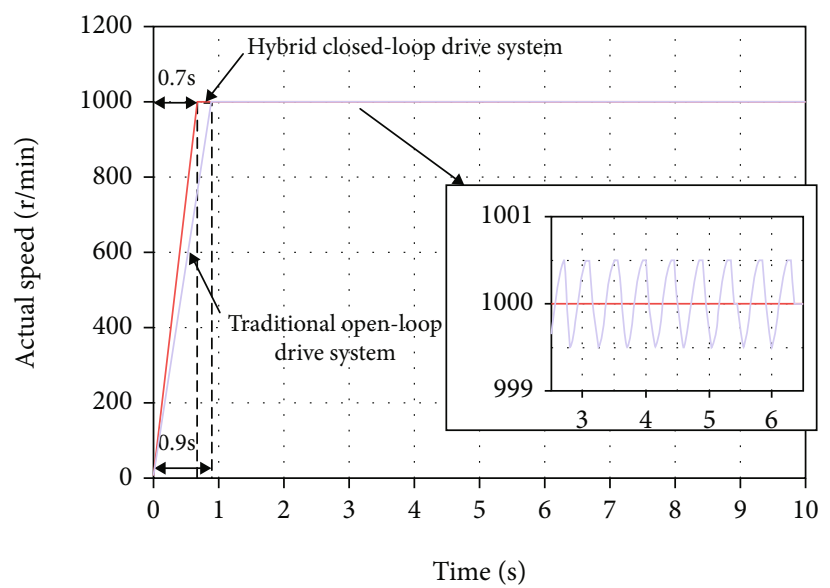

FIgURE 6: Comparison of motor speed curves at a given speed $1000 \mathrm{r} / \mathrm{min}$.

$$
i_{\text {ref }}= \begin{cases}i_{\text {openhold }}, & \left|e_{\text {pos }}\right|<\theta_{\text {open }}, \\ i_{\text {openrun }}, & \theta_{\text {open }} \leq\left|e_{\text {pos }}\right|<\theta_{\text {close }} \\ i_{\text {closerun }}, & \left|e_{\text {pos }}\right| \geq \theta_{\text {close }}\end{cases}
$$




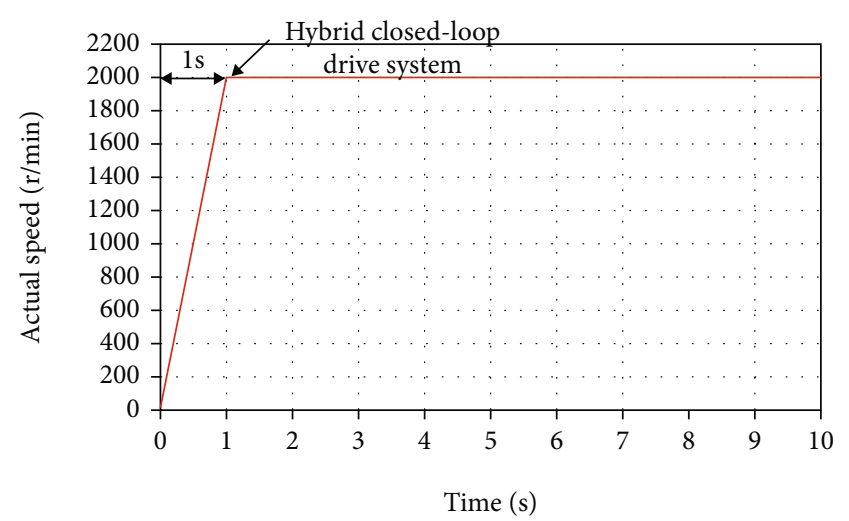

FIgURE 7: Comparison of motor speed curves at a given speed $2000 \mathrm{r} / \mathrm{min}$.

$$
\begin{aligned}
\theta_{g} & = \begin{cases}\theta_{i}, & \text { Mode }=0, \\
\theta_{\text {ref }}, & \text { Mode }=1, \\
\theta_{\text {fed }}+\theta_{c}, & \text { Mode }=2,\end{cases} \\
i_{\alpha \text { ref }}= & \mathrm{i}_{\text {ref }} \times \cos \left(\theta_{g}\right), \\
i_{\beta \text { ref }}= & \mathrm{i}_{\text {ref }} \times \sin \left(\theta_{g}\right), \\
i_{\text {openrun }}= & \mathbf{I} \mathbf{p} \times\left(P_{\text {openhold }}+\frac{\left(P_{\text {closehold }}-P_{\text {openhold }}\right)}{\theta_{\text {close }}-\theta_{\text {open }}}\left(\left|e_{\text {pos }}\right|-\theta_{\text {open }}\right)\right) .
\end{aligned}
$$

2.2. Leading Angle Control Based on Position Error Integration Feedforward. In this paper, a lead angle control method based on error-integrated feedforward compensation is proposed. The lead angle consists of two parts: position error lead angle and speed error lead angle. The calculation method is shown in formula (5), where $\mathrm{Kp}_{p}$ and $\mathrm{Kp}_{n}$ are the feedforward proportional coefficients of position error and velocity error, respectively.

$$
\theta_{c}=\mathrm{Kp}_{p} \times e_{\mathrm{pos}}+\mathrm{Kp}_{n} \times e_{n}
$$

\section{Experimental Test}

To verify the correctness and superiority of the proposed method, this paper designs the software and hardware of the driver and the corresponding test platform (as shown in Figure 3). Based on this, a closed-loop drive system based on the hybrid controller (hereinafter referred to as the hybrid closed-loop drive system) and the performance comparison test of the traditional open-loop stepping motor drive system (hereinafter referred to as the traditional open-loop drive system), the relevant parameters of the stepper motor and the drive system are shown in Table 1.

3.1. Speed Control. The comparison test was carried out under no load, given the speed of $10 \mathrm{r} / \mathrm{min}$, and the obtained motor speed waveform is shown in Figure 4. By observing the waveform, the motor of the hybrid closed-loop drive system rises to a given speed for about $0.05 \mathrm{~s}$, and the rotational speed error of the steady-state process is almost $0 \mathrm{rpm}$. The motor of the traditional open-loop drive system responds slowly, rising to a given speed for about $0.07 \mathrm{~s}$, but the rotational speed error of the steady-state process is also almost $0 \mathrm{rpm}$. Therefore, it is experimentally known that at the low-speed start, the closed-loop drive system is faster than the open-loop drive system for the response time of the motor, but in steady-state operation, the steady-state error of the closed-loop drive system and the open-loop drive system is both 0 .

The comparison test was carried out under no load, given the speed of $400 \mathrm{r} / \mathrm{min}$, and the obtained motor speed waveform is shown in Figure 5. By observing the waveform, the motor of the hybrid closed-loop drive system rises to a given speed for about $0.4 \mathrm{~s}$, and the motor's rotational speed error is $0 \mathrm{rpm}$ during steady-state operation. The motor response of the traditional open-loop drive system is slower, rising to about $0.5 \mathrm{~s}$ ( $0.6 \mathrm{~s}$ in Figure 5). For constant speed, the motor's rotational speed error during steady-state operation is $0 \mathrm{r} / \mathrm{min}$. Therefore, it is experimentally known that the response time of the closed-loop drive system motor is faster than that of the open-loop drive system under no load and given speed $400 \mathrm{r} / \mathrm{min}$. However, the steady-state error of both the closed-loop drive system and the open-loop drive system during steady-state operation is zero.

The comparison test was carried out under no load, given the speed of $1000 \mathrm{r} / \mathrm{min}$, and the obtained motor speed waveform is shown in Figure 6. By observing the waveform, the motor of the hybrid closed-loop drive system rises to a given speed for about $0.7 \mathrm{~s}$, and the motor's rotational speed error is $0 \mathrm{r} / \mathrm{min}$ during steady-state operation. The motor of the traditional open-loop drive system responds slowly, rising to a given speed for about $0.9 \mathrm{~s}$, and the motor speed error during steady-state operation is $\pm 0.5 \mathrm{r} / \mathrm{min}$. Therefore, it is experimentally known that when given speed is $1000 \mathrm{r} / \mathrm{min}$ with no load, the response time of the closed-loop drive system motor is faster than that of the open-loop drive system. In the steady-state process, the open-loop drive system begins to show steady-state error. The steady-state error of the closed-loop drive system is still zero.

The comparison test was carried out under no load, given the speed of $2000 \mathrm{r} / \mathrm{min}$, and the obtained motor speed waveform is shown in Figure 7. By observing the waveform, the motor of the hybrid closed-loop drive system rises to a given speed after about $1 \mathrm{~s}$, and the motor's rotational speed error is $\pm 0.5 \mathrm{r} / \mathrm{min}$ during steady-state operation. The conventional open-loop drive system motor starts out of step at this given speed and does not reach the given speed. Therefore, it is experimentally known that the closed-loop drive system has a higher maximum speed than the open-loop drive system at no load.

3.2. Position Control. According to the performance analysis under the previous speed control, this paper sets the running speed of the motor to $400 \mathrm{r} / \mathrm{min}$ and compares the test with the square wave change between 0 and 5000 pluse at the given position. The obtained test waveform is shown in Figure 8. By observing the waveform, when the actual position of the motor is 0 pluse and the given position is 5000 


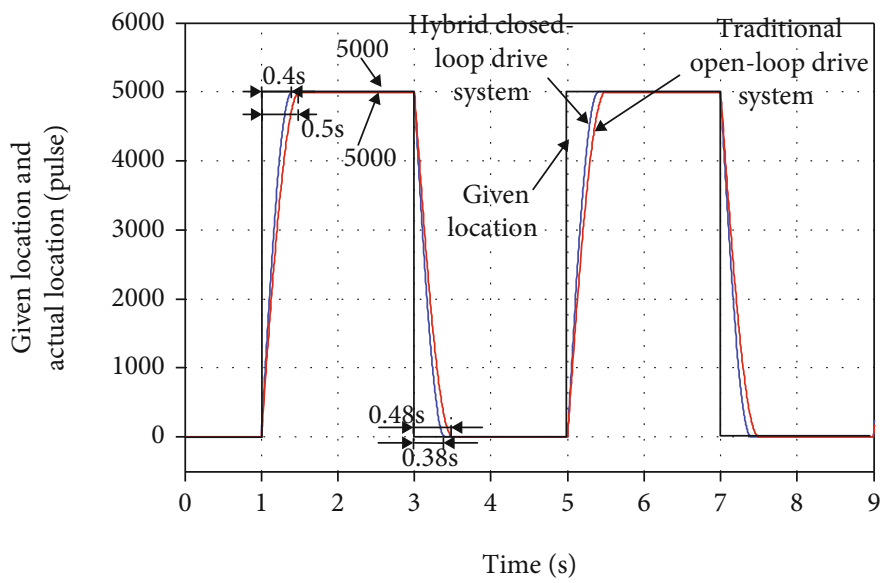

(a) Position curve contrast waveform

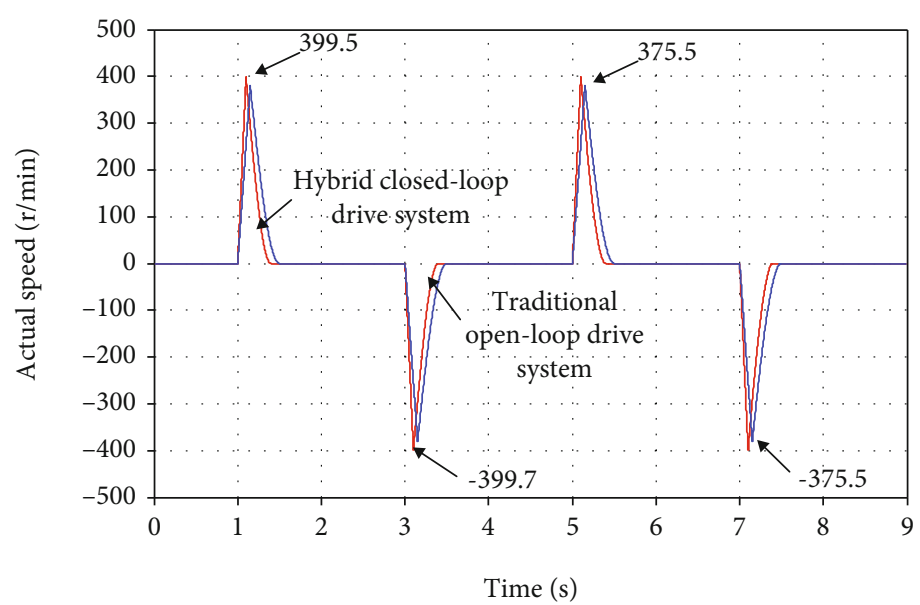

(b) Speed curve contrast waveform

FIGURE 8: A given speed $400 \mathrm{r} / \mathrm{min}$ and a given position 5000 pluse of motor position contrast waveform.

pluse, the motor of the traditional open-loop drive system reaches the given position for about $0.5 \mathrm{~s}$ and the highest forward speed of the motor is $375.5 \mathrm{r} / \mathrm{min}$, and the hybrid motor of the closed-loop drive system reaches the given position in about $0.4 \mathrm{~s}$ and the maximum forward speed of the motor is $399.5 \mathrm{r} / \mathrm{min}$. In the steady-state process, the position error of both systems is 0 pluse. Therefore, from the experimental results, the positioning response performance of the closedloop drive system is better than that of the open-loop drive system. Under the condition of no load and set running speed of $400 \mathrm{r} / \mathrm{min}$, the positioning accuracy of the two systems is similar.

Secondly, set the running speed of the motor to $1000 \mathrm{r} / \mathrm{min}$, and the test waveform obtained by comparing the test with the square wave change between 0 and 20000 pluse at a given position is shown in Figure 9. Observing the waveform shows that when the actual position of the motor is 0 pluse and the given position is 20000 pluse, the motor of the traditional open-loop drive system reaches the given position in about $1.6 \mathrm{~s}$ and the maximum forward speed of the motor is $1000 \mathrm{r} / \mathrm{min}$. The motor of the hybrid closed-loop drive system reaches the given position in about $1.4 \mathrm{~s}$. The maximum forward speed of the motor is
$1000 \mathrm{r} / \mathrm{min}$; in the steady-state process, the position error of the motor of the conventional open-loop drive system is 2 pluse; the position error of the motor of the hybrid closedloop drive system is 0 pluse. Therefore, it is known from the experimental results that the hybrid closed-loop drive system has better positioning response performance than the traditional open-loop drive system. In the case of no load, set the running speed to $1000 \mathrm{r} / \mathrm{min}$; the hybrid closed-loop drive system has higher positioning precision.

Also, according to the performance analysis under the previous speed control, considering the no load, the maximum operating speed of the traditional open-loop drive system is $1000 \mathrm{r} / \mathrm{min}$, and the speed of the hybrid closed-loop drive system can be up to $2000 \mathrm{r} / \mathrm{min}$. This paper is based on the experimental phenomena in Figure 9. Set the given speed of the hybrid closed-loop drive system motor to $2000 \mathrm{r} / \mathrm{min}$, and also perform the comparison test under the condition that the square wave changes between 0 and 20000 pluse at a given position. The obtained test waveform is shown in Figure 10. By observing the waveform, when the actual position of the motor is 0 pluse and the given position is 20000 pluse, the motor of the hybrid closed-loop drive system reaches the given position after about $0.8 \mathrm{~s}$ and the 


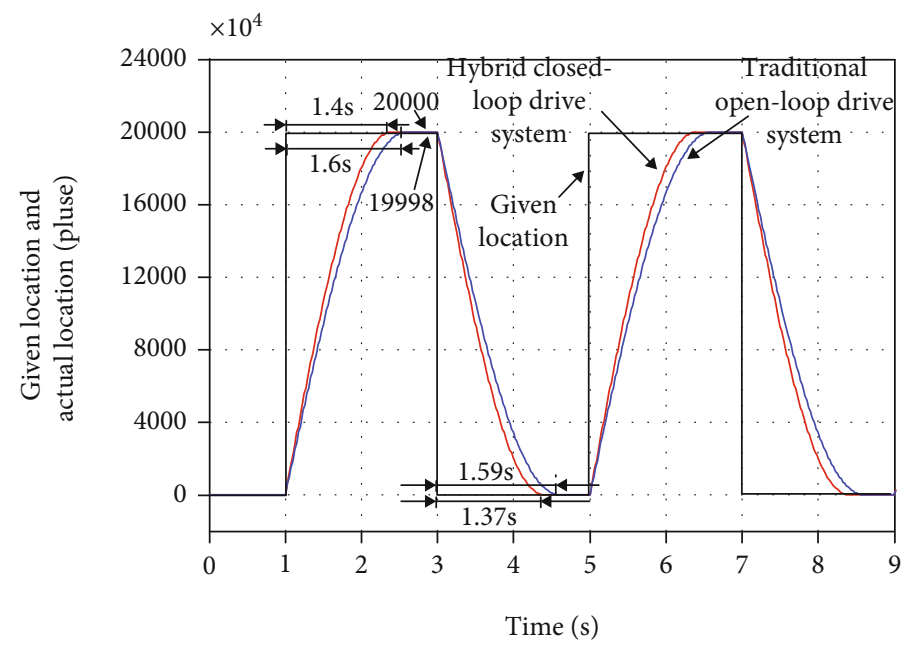

(a) Position curve contrast waveform

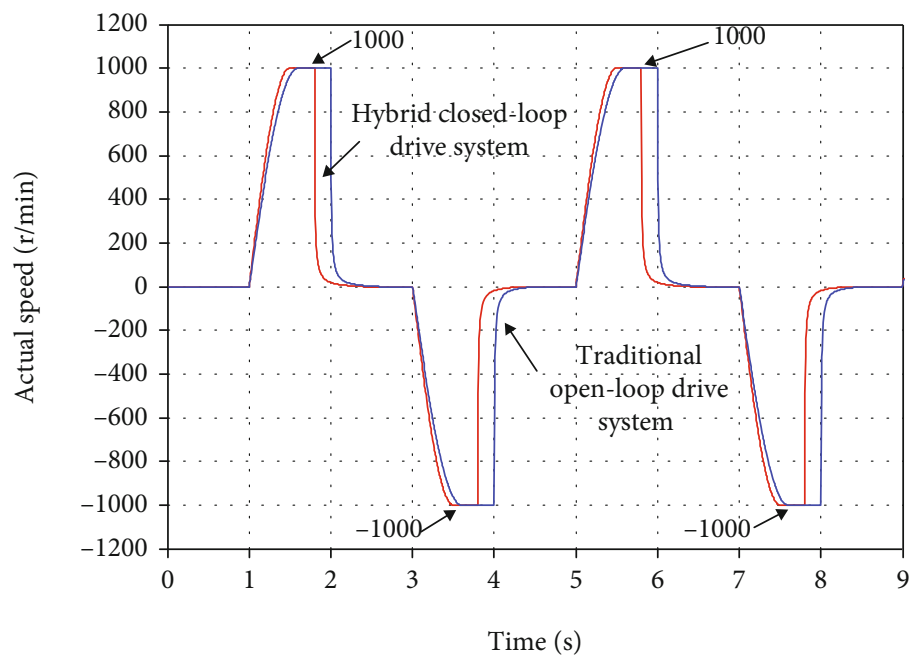

(b) Speed curve contrast waveform

FIgURE 9: A given speed $1000 \mathrm{r} / \mathrm{min}$ and a given position 20000 pluse of motor high-speed positioning contrast waveform.

highest forward speed of the motor is $2000 \mathrm{r} / \mathrm{min}$. In the steady-state process, the position error of the hybrid closedloop drive system is 0 pluse. Therefore, the hybrid closedloop drive system can further improve the positioning response speed by increasing the running speed compared to the conventional open-loop drive system when given in the same position.

3.3. Mechanical Characteristic Curve Test. In this paper, several sets of different speeds are set for the hybrid closed-loop drive system and the traditional open-loop drive system, respectively. The steady-state load test of the motor is performed sequentially in each set of speeds, and the maximum load torque of the system at this set of speeds is recorded. Then, through these sets of data, the mechanical characteristics of the two systems drawn are shown in Figure 11. By observing the curve, the maximum load torque of the hybrid closed-loop drive system is greater than that of the conventional open-loop drive system at the same speed. At a given speed of $1000 \mathrm{r} / \mathrm{min}$, the maximum load torque of the hybrid closed-loop drive system is $2 \mathrm{~N} \cdot \mathrm{m}$, while that of the conventional open-loop drive system is $0.3 \mathrm{~N} \cdot \mathrm{m}$. At no load, the maximum operating speed of the hybrid closed-loop drive system is $2000 \mathrm{r} / \mathrm{min}$, while the maximum operating speed of the conventional open-loop drive system is $1000 \mathrm{r} / \mathrm{min}$. Therefore, the traditional open-loop stepper motor drive system increases the effective load torque by $81.25 \%$ and the maximum operating speed by $50 \%$ when designed with the proposed scheme.

3.4. On-Load Drive Performance Test. Based on the driving performance test of the first two systems under no-load conditions and the mechanical characteristic curve of Figure 11, the driving performance test under the condition of system loading is performed below.

Firstly, in the case of a given square speed change of $400 \mathrm{r} / \mathrm{min}$ and a given position of $0-5000$ pluse, the system is subjected to a comparison test of no-load and load phases; according to Figure 11, the torque corresponds to the mechanical characteristics of the traditional open-loop drive 


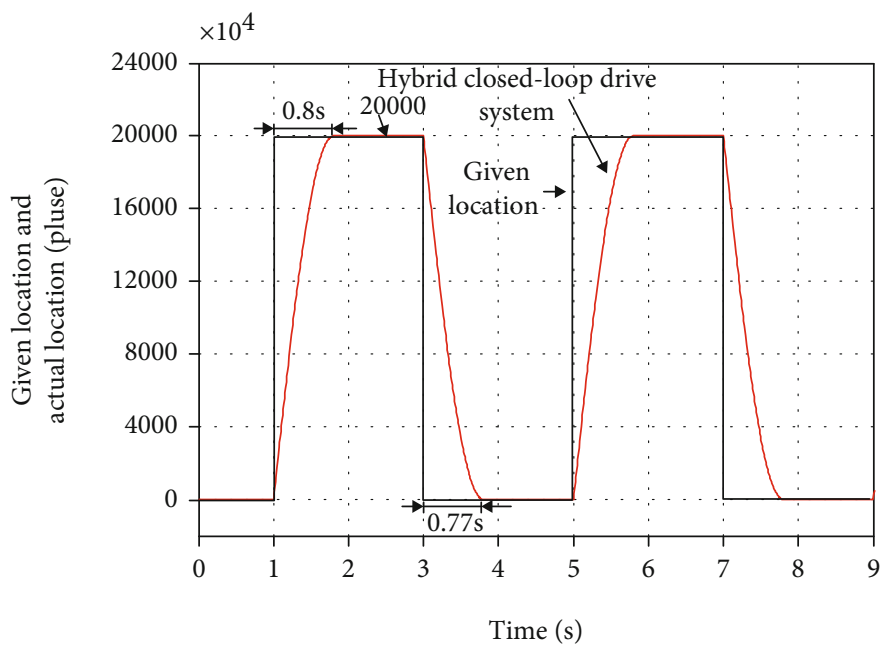

(a) Position curve contrast waveform

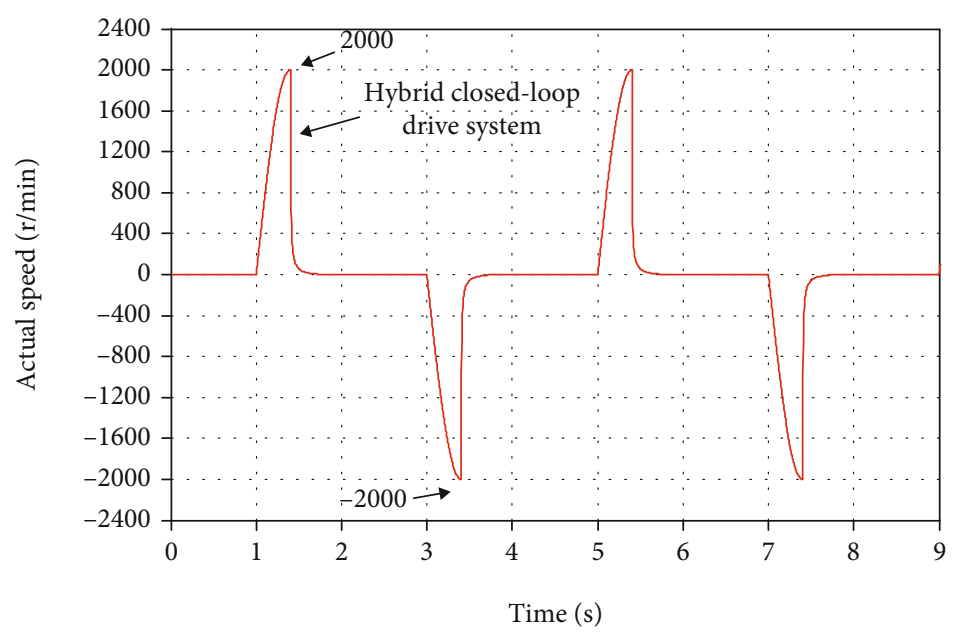

(b) Speed curve contrast waveform

FIGURE 10: A given speed $2000 \mathrm{r} / \mathrm{min}$ and a given position 20000 pluse of motor high-speed positioning contrast waveform.

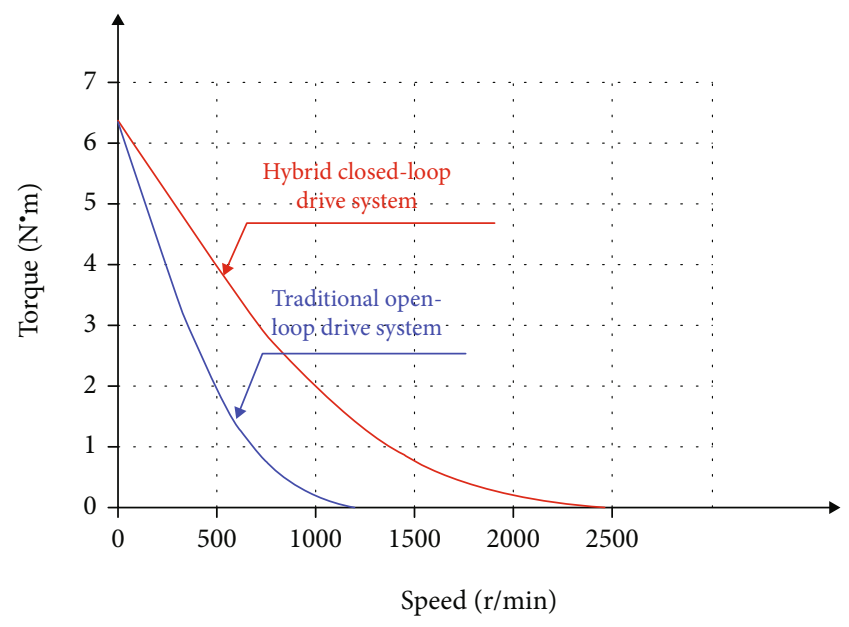

FIGURE 11: Mechanical characteristic curves of two drive systems.

system at $400 \mathrm{r} / \mathrm{min}$. Set the load torque of the motor to $2.5 \mathrm{~N} \cdot \mathrm{m}$, and the resulting test waveform is shown in Figure 12. By observing the waveform, it can be seen that in the first-stage system no-load operation, the actual position of the traditional open-loop drive system rises from 0 to a given position for $0.5 \mathrm{~s}$, the highest forward speed of the motor is $375.5 \mathrm{r} / \mathrm{min}$, and the positioning error is 0 pluse. The actual position of the hybrid closed-loop drive system rises to a given position for approximately $0.4 \mathrm{~s}$. The maximum forward speed of the motor is $399.5 \mathrm{r} / \mathrm{min}$, and the positioning error is 0 pluse. In the second stage, manually loading $2.5 \mathrm{~N} \cdot \mathrm{m}$ and observing the waveform, we can see that the actual position of the traditional open-loop drive system and the given position have an error in the steady-state process ( -70 pluse), which cannot be reached in the same square wave change period. At the given position, the maximum forward speed of the motor drops from $375.5 \mathrm{r} / \mathrm{min}$ to $360 \mathrm{r} / \mathrm{min}$; the actual position of the motor of the hybrid closed-loop step drive system rises to the given position for approximately $0.42 \mathrm{~s}$, and the maximum forward speed of the motor is still $399.5 \mathrm{r} / \mathrm{min}$ and the positioning error is still 0 pluse. Therefore, compared with the experimental results, the application of load reduces the speed and positioning accuracy of the traditional open-loop system, the hybrid 


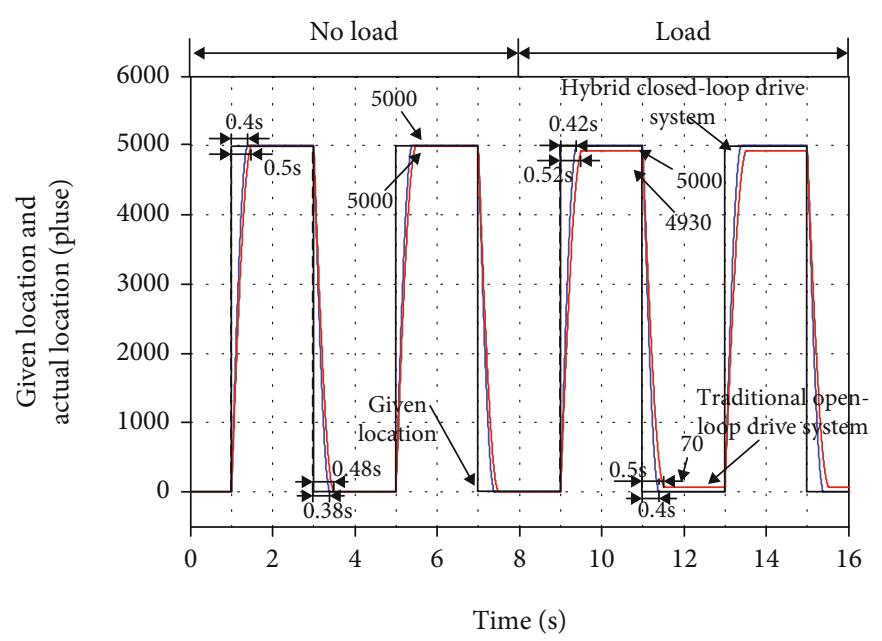

(a) Position curve

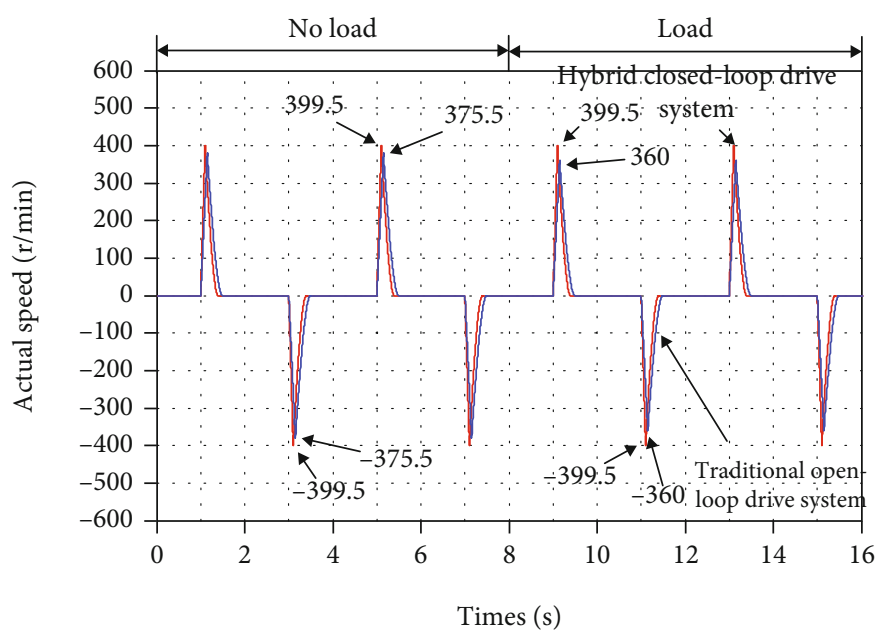

(b) Speed curve

FIGURE 12: Set a test with a running speed of $500 \mathrm{r} / \mathrm{min}$, a given position of 5000 pluse, and a sudden plus $2.5 \mathrm{~N} \cdot \mathrm{m}$ load.

closed-loop drive system designed in this paper can still follow the given position well in the process of sudden loading, and the positioning accuracy has been improved.

Secondly, according to the mechanical characteristics of the hybrid closed-loop drive system in Figure 11, the corresponding torque at $400 \mathrm{r} / \mathrm{min}$ is set to $4.2 \mathrm{~N} \cdot \mathrm{m}$ for the motor; at a given speed of $400 \mathrm{r} / \mathrm{min}$, the given position is 0 . In the case of a square wave change at 5000 pluse, the system is retested in two stages of no load and loading, and the experimental phenomenon is observed. The traditional open-loop drive system has an out-of-step shutdown phenomenon, and the experimental waveform of the hybrid closed-loop drive system is shown in Figure 13; in the first stage of the system, the actual position of the hybrid closed-loop drive system rises to the given position for approximately $0.4 \mathrm{~s}$, and the highest forward speed of the motor is $399.5 \mathrm{r} / \mathrm{min}$. The error is 0 pluse; in the second stage, manually load $4.2 \mathrm{~N} \cdot \mathrm{m}$, observe the waveform, the actual position of the hybrid closed-loop drive system rises to the given position for about $0.42 \mathrm{~s}$, the highest forward speed of the motor is still $399.5 \mathrm{r} / \mathrm{min}$, and the positioning error is still 0 pluse. Therefore, compared with the traditional open-loop drive system, the hybrid closed-loop drive system has a higher load-carrying capacity while improving the positioning accuracy.

Under the condition that the given speed is $1000 \mathrm{r} / \mathrm{min}$ and the given position is $0-20000$ pluse, the system is tested in two stages of no load and loading. According to the mechanical characteristics of the traditional open-loop drive system in Figure 11, the corresponding moment at $1000 \mathrm{r} / \mathrm{min}$ is set to be $0.3 \mathrm{~N} \cdot \mathrm{m}$, and the test wave is obtained. It is shown in Figure 14. The observed waveforms show that in the first stage of no-load operation, the actual position of the traditional open-loop drive system rises to a given position after $1.6 \mathrm{~s}$, the maximum forward speed of the motor is $1000 \mathrm{r} / \mathrm{min}$, and the positioning error is 2 pluse; the actual position of the hybrid closed-loop drive system rises to a given position after $1.4 \mathrm{~s}$, and this is the maximum positive position of the motor. The speed is $1000 \mathrm{r} / \mathrm{min}$, and the positioning error is 0 pluse. In the second stage, $0.3 \mathrm{~N} \cdot \mathrm{m}$ is loaded manually, and the observed waveforms show that the actual position and given position of the traditional open-loop drive system have errors in the steady-state process (-190 pluse). 


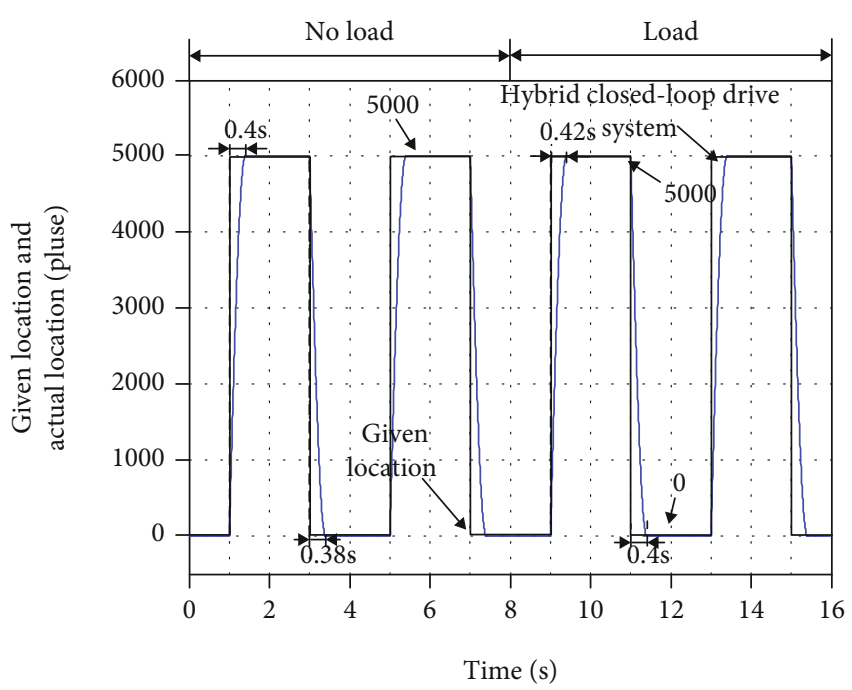

(a) Position curve

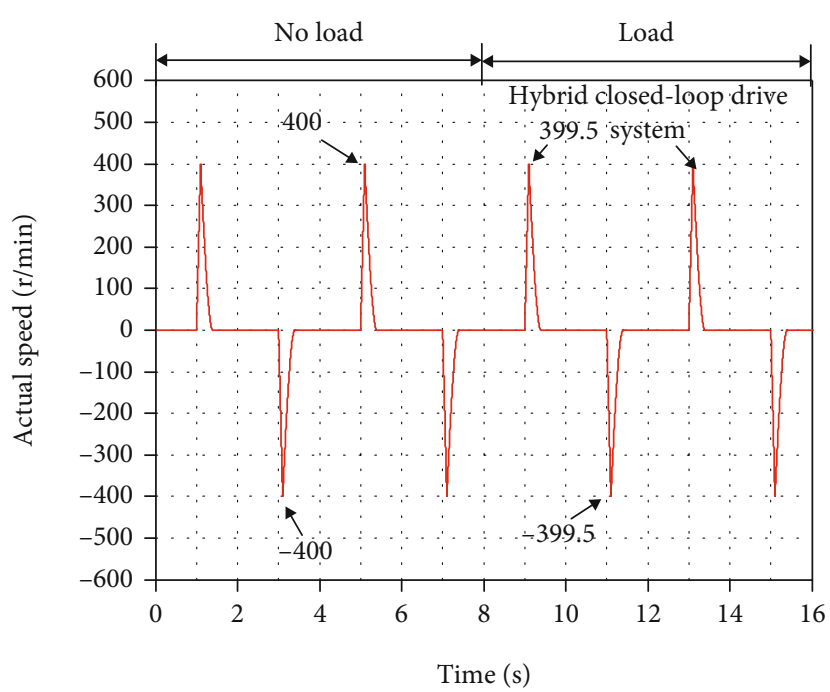

(b) Speed curve

FIGURE 13: Set a test with a running speed of $500 \mathrm{r} / \mathrm{min}$, a given position of 5000 pluse, and a sudden plus $4.2 \mathrm{~N} \cdot \mathrm{m}$ load.

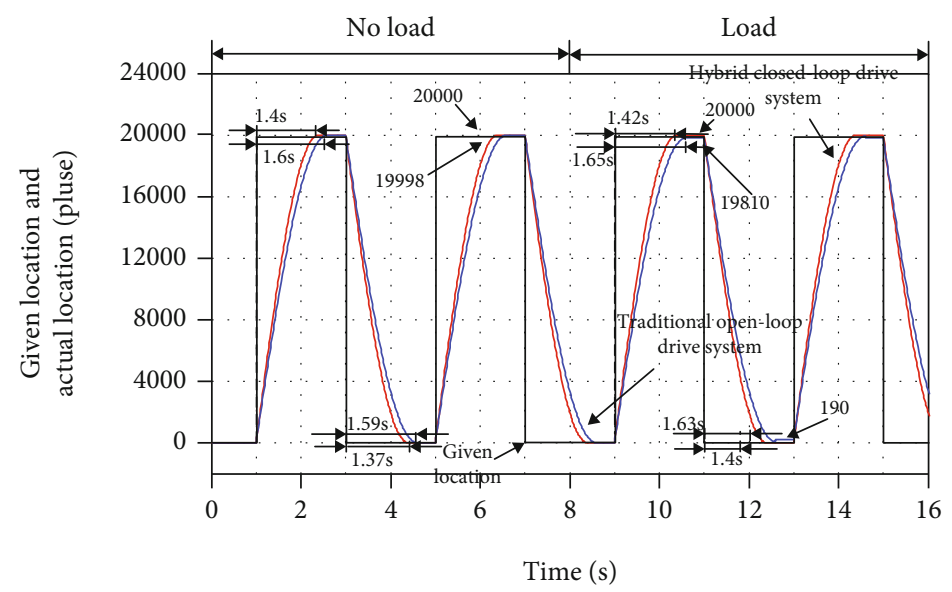

(a) Position curve

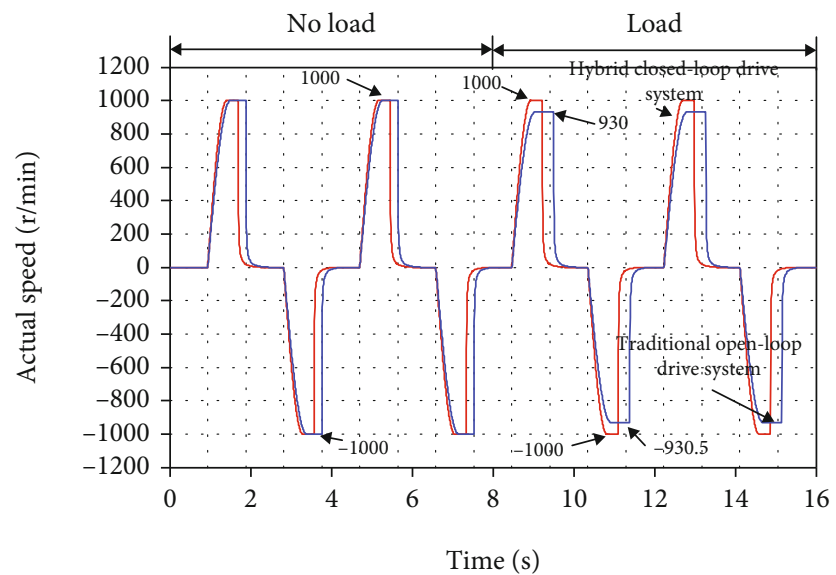

(b) Speed curve

FIGURE 14: Set a test with a running speed of $1000 \mathrm{r} / \mathrm{min}$, a given position of 20000 pluse, and a sudden plus $0.3 \mathrm{~N} \cdot \mathrm{m}$ load. 


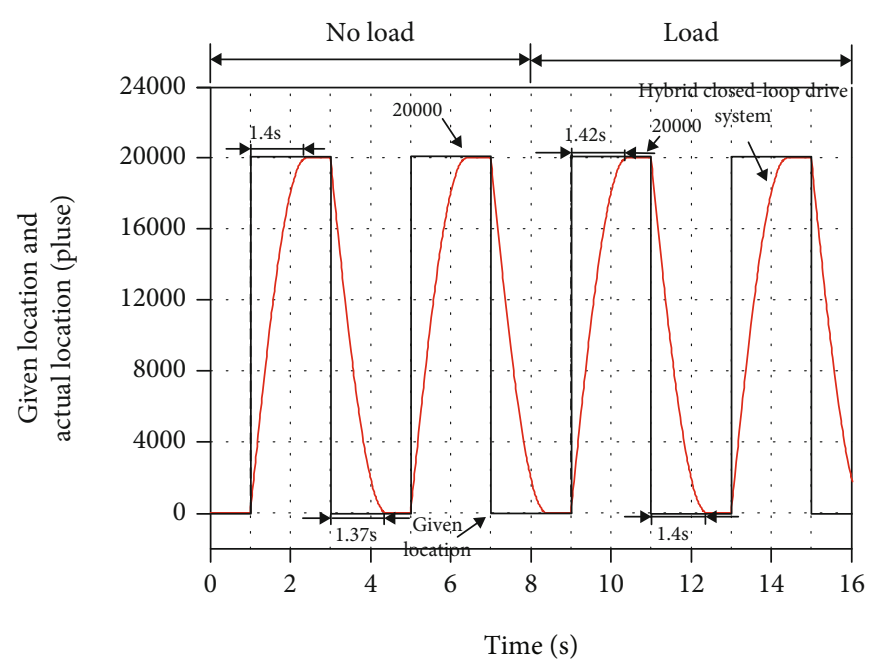

(a) Position curve

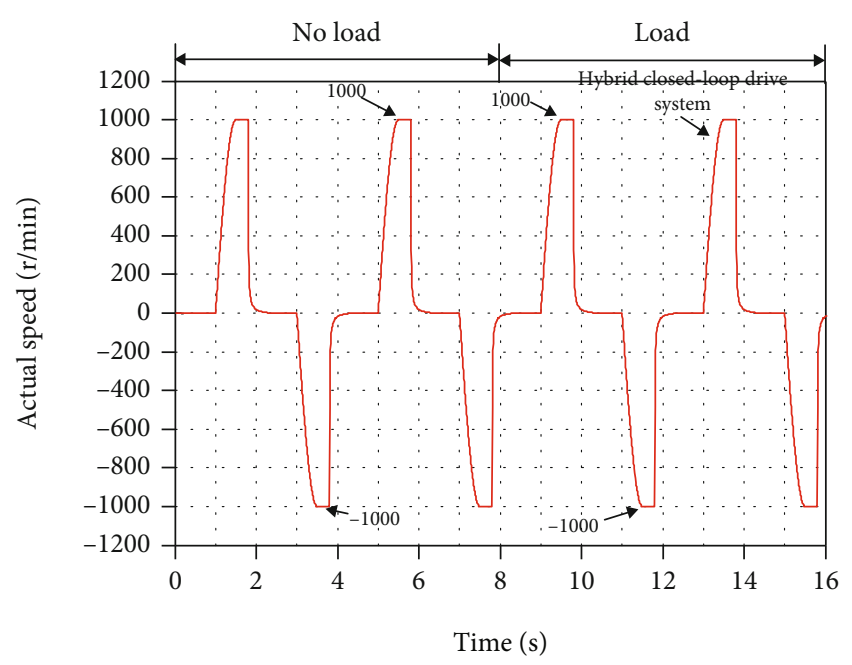

(b) Speed curve

FIgURE 15: Set a test with a running speed of $1000 \mathrm{r} / \mathrm{min}$, a given position of 20000 pluse, and a sudden plus $2 \mathrm{~N} \cdot \mathrm{m}$ load.

Within the same square wave change period, the given position cannot be reached. The maximum forward speed of the motor decreases from $1000 \mathrm{r} / \mathrm{min}$ to $930 \mathrm{r} / \mathrm{min}$; the actual position of the hybrid closed-loop drive system rises to a given position after $1.42 \mathrm{~s}$. The maximum forward speed of the motor is $1000 \mathrm{r} / \mathrm{min}$, and the positioning error is still 0 pluse. Therefore, compared with the experimental results, the application of load reduces the speed and positioning accuracy of the traditional open-loop system, the hybrid closed-loop drive system designed in this paper can still follow the given position well in the process of sudden loading, and the positioning accuracy has been improved.

Then, according to the mechanical characteristics of the hybrid closed-loop drive system in Figure 11, with the corresponding torque at the $1000 \mathrm{r} / \mathrm{min}$, the loading torque of the set motor is $2 \mathrm{~N} \cdot \mathrm{m}$, in the case of a given speed of $1000 \mathrm{r} / \mathrm{min}$ and a given position of $0-20000$ pluse in the square wave change. The system is compared with two stages of no load and loading. Observe the test phenomenon, the traditional open-loop drive system has an out-of-step downtime phenomenon, and the hybrid closed-loop drive system test waveform is shown in Figure 15; in the first stage of the system no-load operation, the actual position of the hybrid closed-loop drive system rises from about $1.4 \mathrm{~s}$ to a given position, the maximum forward rotational speed of the motor is $1000 \mathrm{r} / \mathrm{min}$, and the positioning error in the steady-state process is 0 pluse. In the second stage, manually load $2 \mathrm{~N} \cdot \mathrm{m}$, observe the waveform, the actual position of the hybrid closed-loop drive system rises from about $1.42 \mathrm{~s}$ to a given position, the maximum forward rotational speed of the motor is $1000 \mathrm{r} / \mathrm{min}$, and the positioning error is still 0 pluse. Therefore, compared with the traditional open-loop drive system, the hybrid closed-loop drive system can improve the positioning accuracy and its carrying capacity is stronger.

\section{Conclusion}

To improve the positioning accuracy and carrying capacity of the two-phase hybrid stepper motor at high speed of the motor, this paper presents a high-speed and high-overload drive method and system based on the hybrid controller, which contains the following two core contents:

(1) A hybrid controller based on position error for openloop/closed-loop automatic switching, with current amplitude and angle automatic adjustment, is proposed. (b) An advanced angle compensation strategy based on error-integrated feedforward is proposed. The corresponding test platform was set up for testing, and the system was tested to compare the following performance

(2) In the case of no load, the maximum speed of the hybrid closed-loop servo system can reach $2000 \mathrm{r} / \mathrm{min}$, while the maximum speed of the traditional open-loop system is only $1000 \mathrm{r} / \mathrm{min}$, and the high speed running speed of the empty load increases by about $50 \%$

(3) In the case of the empty load with the same given speed and position pulse number, the response time of the mixed closed-loop stepper drive system to reach a given value is faster than that of the traditional open-loop stepper system

(4) At the same operating speed, the carrying capacity of the hybrid closed-loop stepper drive system is greater than that of the traditional open-loop stepper system, and the effective torque can be increased to more than $81.25 \%$ of the retention torque

(5) Compared with the traditional open-loop drive system, the hybrid closed-loop drive system exerts the same load torque at the same given pulse position, 
and the hybrid closed-loop drive systems have faster response speed. In the process of high-speed motion, the hybrid closed-loop drive system can also maintain the high-torque operation, which ensures that the stepper motor has higher positioning accuracy in the working process

\section{Data Availability}

The data used to support the findings of this study are included within the article.

\section{Conflicts of Interest}

The authors declare that they have no conflicts of interest.

\section{Acknowledgments}

This work was supported by the Key Research and Development Program of Science and Technology Department of Zhejiang Province (2021C01071 and 2021C2022).

\section{References}

[1] P. Siripala and Y. A. Sekercioglu, "A generalised solution for generating stepper motor speed profiles in real time," Mechatronics, vol. 23, no. 5, pp. 541-547, 2013.

[2] S. Derammelaere, B. Vervisch, F. de Belie et al., "The efficiency of hybrid stepping motors: analyzing the impact of control algorithms," IEEE Industry Applications Magazine, vol. 20, no. 4, pp. 50-60, 2014.

[3] Z. Dong, "Nonlinear power-level control design for MHTGRs by considering stepper motor dynamics," Progress in Nuclear Energy, vol. 78, pp. 216-230, 2015.

[4] C. Gradl, A. Plöckinger, and R. Scheidl, "Sensorless position control with a hydraulic stepper drive - concept, compression modeling and experimental investigation," Mechatronics, vol. 35, pp. 91-101, 2016.

[5] A. Bellini, C. Concari, G. Franceschini, and A. Toscani, "Mixed-mode PWM for high-performance stepping motors," IEEE Transactions on Industrial Electronics, vol. 54, no. 6, pp. 3167-3177, 2007.

[6] J. Pillans, "Reducing position errors by vibration optimization of stepper motor drive waveforms," IEEE Transactions on Industrial Electronics, vol. 68, no. 6, pp. 5176-5183, 2021.

[7] W. Kim, Y. Lee, D. Shin, and C. C. Chung, "Nonlinear gain position control using only position feedback for permanent magnet stepper motors," IEEE Transactions on Power Electronics, vol. 36, no. 7, pp. 8506-8516, 2021.

[8] F. Wang, S. Yuan, and P. Jing, "Research on the fuzzy-based out-of-step preventive control for low-speed permanent magnet linear synchronous motor," in IEEE ICCA 2010, pp. 10251029, Xiamen, China, 2010.

[9] X. Wang, S. Lu, and S. Zhang, "Rotating angle estimation for hybrid stepper motors with application to bearing fault diagnosis," IEEE Transactions on Instrumentation and Measurement, vol. 69, no. 8, pp. 5556-5568, 2020.

[10] S. Moon and D. H. Kim, "Step-out detection and error compensation for a micro-stepper motor using current feedback," Mechatronics, vol. 24, no. 3, pp. 265-273, 2014.
[11] A. Masi, M. Butcher, M. Martino, and R. Picatoste, "An application of the extended Kalman filter for a sensorless stepper motor drive working with long cables," IEEE Transactions on Industrial Electronics, vol. 59, no. 11, pp. 4217-4225, 2012.

[12] M. Bendjedia, Y. Ait-Amirat, B. Walther, and A. Berthon, "Position control of a sensorless stepper motor," IEEE Transactions on Power Electronics, vol. 27, no. 2, pp. 578-587, 2012.

[13] S. Derammelaere, C. Debruyne, F. De Belie, K. Stockman, and L. Vandevelde, "Load angle estimation for two-phase hybrid stepping motors," IET Electric Power Applications, vol. 8, no. 7, pp. 257-266, 2014.

[14] S. Derammelaere, B. Vervisch, J. De Viaene, and K. Stockman, "Sensorless load angle control for two-phase hybrid stepper motors," Mechatronics, vol. 43, no. 3, pp. 6-17, 2017.

[15] S. Derammelaere, F. Verbelen, and K. Stockman, "Robust sensorless load angle control for stepping motors," in 2015 18th International Conference on Electrical Machines and Systems (ICEMS), Pattaya, Thailand, 2015.

[16] W. Kim, C. Yang, and C. C. Chung, "Design and implementation of simple field-oriented control for permanent magnet stepper motors without DQ transformation," IEEE Transactions on Magnetics, vol. 47, no. 10, pp. 4231-4234, 2011.

[17] K. Wonhee, S. Donghoon, and C. C. Chung, "Microstepping with nonlinear torque modulation for permanent magnet stepper motors," IEEE Transactions on Control Systems Technology, vol. 21, no. 5, pp. 1971-1979, 2013.

[18] W. Kim, D. Shin, Y. Lee, and C. C. Chung, "Simplified torque modulated microstepping for position control of permanent magnet stepper motors," Mechatronics, vol. 35, pp. 162-172, 2016.

[19] S.-K. Kim and C. K. Ahn, "Position regulator with variable cutoff frequency mechanism for hybrid-type stepper motors," IEEE Transactions on Circuits and Systems I: Regular Papers, vol. 67 , no. 10, pp. 3533-3540, 2020.

[20] S. Rustemli, M. Yilmaz, and M. Demirtas, "Ripple reduction at speed and torque of step motors used on a two-axis robot arm," Robotics and Computer-Integrated Manufacturing, vol. 26, no. 6, pp. 759-767, 2010.

[21] S. E. Lyshevski, "Microstepping and high-performance control of permanent-magnet stepper motors," Energy Conversion and Management, vol. 85, pp. 245-253, 2014.

[22] A. Arias, J. Caum, and R. Griñó, "Moving towards the maximum speed in stepping motors by means of enlarging the bandwidth of the current controller," Mechatronics, vol. 40, no. 6, pp. 51-62, 2016.

[23] H. M. Hasanien, "FPGA implementation of adaptive ANN controller for speed regulation of permanent magnet stepper motor drives," Energy Conversion and Management, vol. 52, no. 2, pp. 1252-1257, 2011.

[24] Q. N. Le and J.-W. Jeon, "Neural-network-based low-speeddamping controller for a stepper motor with an FPGA," IEEE Transactions on Industrial Electronics, vol. 57, no. 9, pp. 3167$3180,2010$.

[25] X. Liu, S. Zhen, H. Zhao, H. Sun, and Y. Chen, "Fuzzy-set theory based optimal robust design for position tracking control of permanent magnet linear motor," IEEE Access, vol. 7, pp. 153829-153841, 2019. 